\title{
Comparative analysis of the effects of opioids in angiogenesis
}

\author{
Tao Feng $^{1 *}$, Si Zeng ${ }^{2^{*}}$, Jie Ding ${ }^{1}$, Gong Chen ${ }^{1}$, Bin Wang ${ }^{1}$, Daguo Wang ${ }^{1}$, Xueli Li ${ }^{1}$ and Kunfeng Wang ${ }^{1}$
}

\begin{abstract}
Background: Angiogenesis, the formation of blood vessel from pre-existing ones, plays an important role in many pathophysiological diseases, such as cancer. Opioids are often used in clinic for the management of chronic pain in cancer patients at terminal phases. Here, we investigated and compared the effects and mechanisms of four opioids on angiogenesis.

Methods: We performed angiogenesis assays on human umbilical vein endothelial cells (HUVEC) that represent an in vitro model to assess the toxicity of drugs to endothelium.

Results: Morphine and oxycodone at $0.1 \mu \mathrm{M}$ to $100 \mu \mathrm{M}$ dose-dependently increased endothelial cell tube formation and proliferation. We observed the same in endothelial cells exposed to fentanyl at $0.1 \mu \mathrm{M}$ to $10 \mu \mathrm{M}$ but there was a gradual loss of stimulation by fentanyl at $100 \mu \mathrm{M}$ and $1000 \mu \mathrm{M}$. Morphine and fentanyl reduced endothelial cell apoptosis-induced by serum withdrawal whereas oxycodone did not display anti-apoptotic effect, via decreasing Bax level. Oxycodone at the same concentrations was less potent than morphine and fentanyl. Different from other three opioids, codeine at all tested concentrations did not affect endothelial cell tube formation, proliferation and survival. Mechanism studies demonstrated that opioids acted on endothelial cells via $\mu$-opioid receptor-independent pathway. Although we observed the increased phosphorylation of mitogen-activated protein kinase (MAPK) in cells exposed to morphine, fentanyl and oxycodone, the rescue studies demonstrated that the stimulatory effects of morphine but not fentanyl nor oxycodone were reversed by a specific MAPK inhibitor.
\end{abstract}

Conclusion: Our work demonstrates the differential effects and mechanisms of opioids on angiogenesis.

Keywords: Opioids, MAPK, $\mu$-Opioid receptor, Angiogenesis

\section{Background}

Angiogenesis, the formation of blood vessel from already established blood vessels, is required for tumor progression and metastasis [1]. Vascular endothelial growth factor (VEGF)-A and its receptor VEGFR-2, play an essential role in angiogenesis via various mechanisms, and inhibiting VEGF-VEGFR is a promising

\footnotetext{
*Correspondence: Dr_fengtao@sina.com; xzyxyzs@hotmail.com

${ }^{1}$ Department of Anesthesiology, Affiliated Baoan Central Hospital

of Guangdong Medical University, No 60 Leyuan Road, Baoan Distric of Shenzhen, Shenzhen, Guangdong Province, China

${ }^{2}$ Department of Anesthesiology, Sichuan Academy of Medical Science \& Sichuan Provincial People's Hospital, Electronic Science and Technology

University, 18 Huanhua Road, Chengdu, China
}

therapeutic approach for cancer [2]. Opioids are widely used medication for pain management in several medical conditions including cancer. Opioids act on central nervous system via binding and activating opioid receptors that express pain transmission and modulate pathways [3]. Opioid receptors are members of the G protein coupled receptor superfamily and are classified as $\mu, \delta$ and $\kappa$. Apart from neuron cells, opioid receptors are found to be expressed in other types of cells, such as endothelial and immune cells, resulting in various systematic impacts $[4,5]$. The effects of opioids on both cancer and angiogenesis are highly contentious as both pro- and anti- effects of tumor growth and neovascularization are reported $[6,7]$. original author(s) and the source, provide a link to the Creative Commons licence, and indicate if changes were made. The images or other third party material in this article are included in the article's Creative Commons licence, unless indicated otherwise in a credit line to the material. If material is not included in the article's Creative Commons licence and your intended use is not permitted by statutory regulation or exceeds the permitted use, you will need to obtain permission directly from the copyright holder. To view a copy of this licence, visit http://creativecommons.org/licenses/by/4.0/. The Creative Commons Public Domain Dedication waiver (http://creativeco mmons.org/publicdomain/zero/1.0/) applies to the data made available in this article, unless otherwise stated in a credit line to the data. 
Morphine, fentanyl, oxycodone and codeine are $\mu$-opioid receptor agonists but can bind to and activate $\delta$ and $\kappa$ with differential affinity [8]. Among these four commonly used opioids, morphine has been mostly studied under preclinical settings for its direct effect on tumor cell and angiogenesis but the conclusions are contradictory [9-12]. Morphine stimulates angiogenesis under serum deprivation and oxidative stress conditions [9] whereas also suppresses angiogenesis associated with tumor growth in mice [13]. One study demonstrates that fentanyl stimulates angiogenesis in diabetic rats and promotes wound healing [14]. Another recent study using cell models reveals that fentanyl stimulates tumor angiogenesis [15]. The effects of oxycodone and codeine in angiogenesis are unknown. In this study, we systematically evaluated and compared the effects of all four opioids on tube formation, proliferation, migration and survival of endothelial cells. We further annotated the underlying mechanisms of opioids in endothelial cells.

\section{Methods}

\section{Endothelial cell isolation and culture}

Human umbilical vein endothelial cells (HUVECs) were isolated from human umbilical cord vein using the protocol described in Crampton et al's work [16] with modification. Briefly, the fresh umbilical cords were collected from consented maternal ward patients at the Baoan Central Hospital of Shenzhen, which was approved by the institutional ethics approval committee. Adapters were inserted into vein at each end of the cord and secured tightly with silk thread. The vein was flushed with PBS and then incubated with $0.2 \%$ collagenase (Sigma) for 15 mins at room temperature. Collagenase solutions were warmed up to $37^{\circ} \mathrm{C}$ in water bath prior to injecting into umbilical vein lumen. The released HUVECs together with collagenase were collected and spin down. The cell pelleted were resuspended with PBS and washed twice. Isolated HUVECs were cultured using CSC complete medium (Cell Systems) supplemented with $50 \mu \mathrm{g} / \mathrm{ml}$ gentamycin (Sigma) on $0.2 \%$ gelatine (Sigma)-coated flask. Cells were starved in basal CSC medium (Cell Systems) containing 2\% FBS (starving medium) prior to all experiments.

\section{Drugs, antibodies and reagents}

Morphine-HCL (Sintetica), fentanyl (Yichang Humanwell Pharmaceutical Co., Ltd) and oxycodone hydrochloride tablet (Sankyo Pharmaceutical Co. Ltd.) were obtained
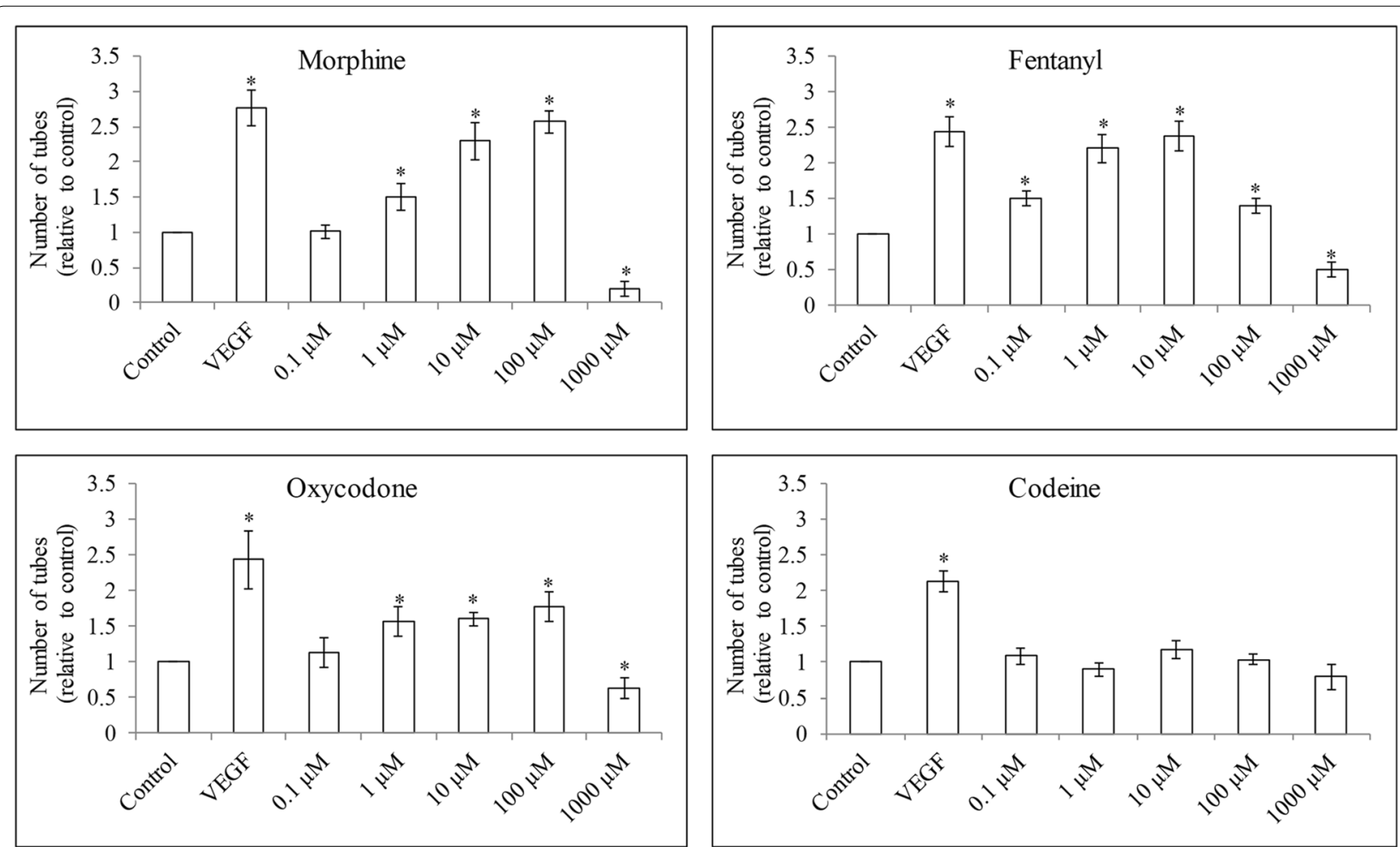

Fig. 1 The effects of opioids in in vitro angiogenesis. Morphine, fentanyl and oxycodone at $0.1 \mu \mathrm{M}$ to $100 \mu \mathrm{M}$ increased capillary network formation whereas at $1000 \mu \mathrm{M}$ decreased capillary network formation. Codeine at $0.1 \mu \mathrm{M}$ to $1000 \mu \mathrm{M}$ did not affect capillary network formation. VEGF at $15 \mathrm{ng} /$ $\mathrm{ml}$ was used. Results shown are relative to control. Each experiment was repeated three times in triplicate, and each value indicates mean \pm SD. ${ }^{*} p<0.05$, compared to control 
from the Department of Pharmacy, Baoan Central Hospital of Shenzhen. Codeine and PD98059 were obtained from Sigma and Selleckchem. Recombinant human VEGF was obtained from R\&D Systems. p-Erk1/2(T202/T204), Erk1/2, Bax and Bcl-2 were purchased from Cell Signaling.

\section{In vitro angiogenesis assay}

In vitro angiogenesis was performed using standard protocol [17]. Briefly, corning Matrigel growth factor reduced basement membrane matrix was thawed on ice. $100 \mathrm{ul}$ was plated onto 96-well-plate and incubated at $37^{\circ}$ $\mathrm{C}$ for $1 \mathrm{~h}$ to allow the matrix solution to solidify. HUVECs at 2000 cells together with VEGF or drugs at different concentrations were suspended in starving medium and plated onto solidified matrix. After $6 \mathrm{~h}$ incubation in a tissue-culture incubator, capillary network structures were documented using an inverted microscope. Tube-like structure length was quantified by measuring the length of branches using Image J software.

\section{Proliferation assay}

Cell proliferation was evaluated by bromodeoxyuridine (BrdU) incorporation method [18]. 10^4 cells were seeded into 96-well plate and incubated overnight. The next day, cells were starved for $3 \mathrm{~h}$ and drugs or VEGF were then added to the starving medium. After 24h drug treatment, BrdU reagent was added into the culture media and proliferation was quantified using BrdU cell proliferation kit (Chemicon) according to manufacturer's instructions.

\section{Boyden chamber migration assay}

We performed migration assay using the Boyden chamber (Cell Biolabs) using the same protocol as described in our previous study [19]. Briefly, cells were placed onto upper chamber and drugs were added to lower chamber. After $8 \mathrm{~h}$ incubation in a tissue-culture incubator, the migrated cells were counted under microscope.

\section{Apoptosis assay}

$10^{\wedge} 5$ cells were seeded into 12 -well plate and incubated overnight. The next day, cells were starved for $3 \mathrm{~h}$ and drugs or VEGF were then added to the starving medium. After $24 \mathrm{~h}$ drug treatment, apoptosis was determined by measuring cytosolic oligonucleosome-bound DNA [20] using a Cell Death ELISA kit (Roche) according to manufacture's instructions.
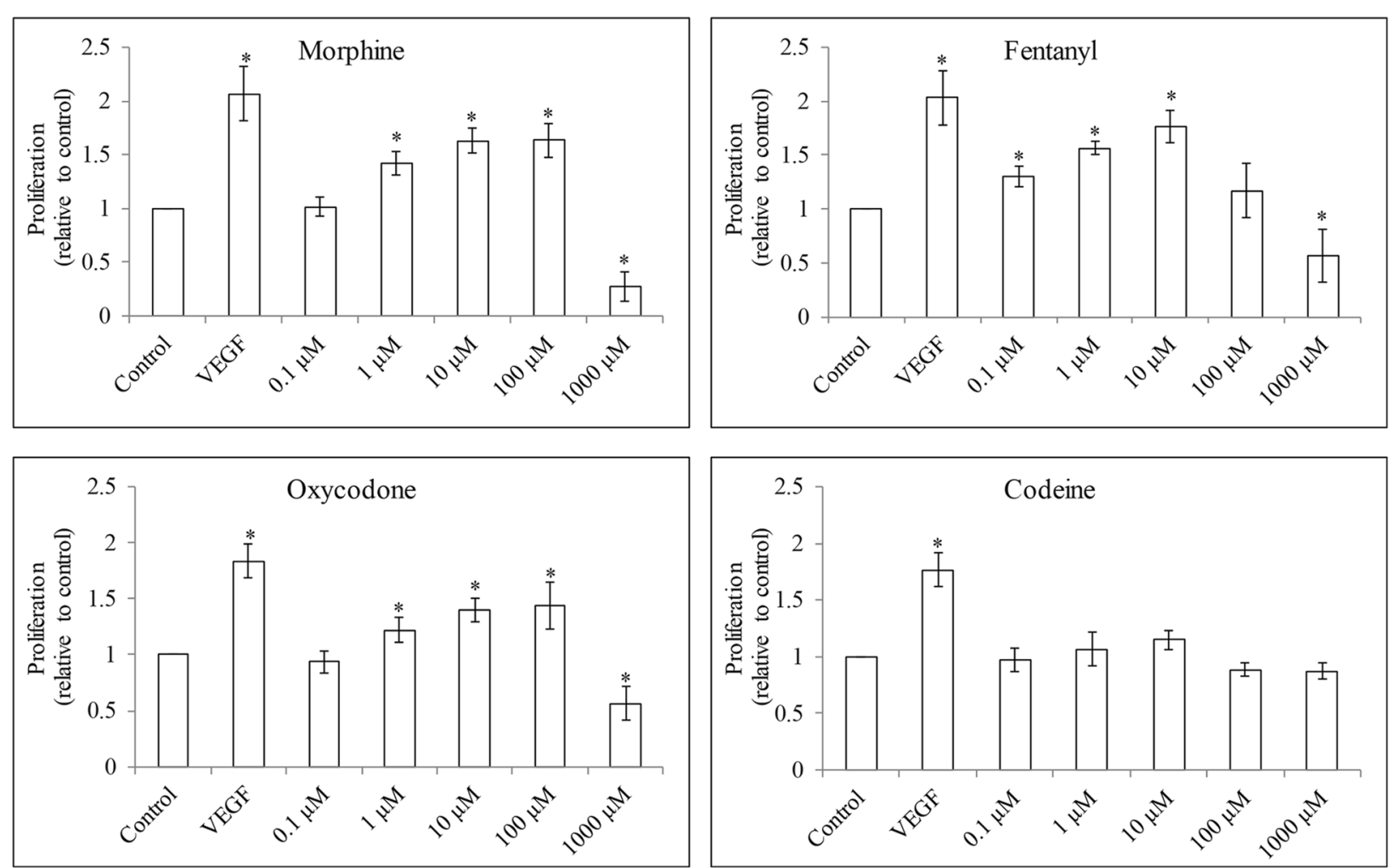

Fig. 2 The effects of opioids in HUVEC proliferation. Morphine, fentanyl and oxycodone at $0.1 \mu \mathrm{M}$ to $100 \mu \mathrm{M}$ increased proliferation whereas at $1000 \mu \mathrm{M}$ decreased proliferation in HUVECs. Codeine at $0.1 \mu \mathrm{M}$ to $1000 \mu \mathrm{M}$ did not affect HUVEC proliferation. VEGF at $15 \mathrm{ng} / \mathrm{ml}$ was used. Results shown are relative to control. Each experiment was repeated three times in triplicate, and each value indicates mean $\pm S D$. ${ }^{*} p<0.05$, compared to control 


\section{Western blot}

$10^{\wedge} 6$ cells were seeded into 6-well plate and incubated overnight. The next day, cells were starved for $3 \mathrm{~h}$ and drugs were then added to the starving medium. After $24 \mathrm{~h}$ drug treatment, cells were harvested for protein extraction using RIPA buffer. Western blot was performed using standard protocol [21]. Briefly, equal amount of proteins was loaded on SDSpolyacrylamide gel, resolved by electrophoresis, transferred to Hybond-C extra nitrocellulose membrane (Amershan-Pharmacia), probed with designated primary and secondary antibodies, and detected using SuperSignal substrate solution (Pierce).

\section{Statistical analyses}

Statistical analyses were performed using unpaired Student's t-test, with $P$-value $<0.05$ as statistically significant. Comparison of three or more categorical variables were performed using ANOVA. All statistical analysis was done on the PRISM statistical software.

\section{Results}

Morphine, fentanyl and oxycodone but not codeine stimulate HUVEC capillary network formation

We evaluated the effects of four commonly used opioids on angiogenesis using in vitro Matrigel matrix angiogenesis assay. HUVECs represent an in vitro model to assess the toxicity of drugs to endothelium and are relevant to the process of pathophysiological angiogenesis [22]. We plated HUVECs on the growth factor reduced basement membrane matrix and used this as control. As a comparison, we included a sample with the addition of $15 \mathrm{ng} / \mathrm{ml}$ VEGF as positive control. Consistent with the previous report [23], we demonstrated that VEGF increased HUVEC tube formation by $\sim 2.5$ fold compared with control (Fig. 1 and Figure S1 to S4). The addition of morphine at concentrations ranging from $0.1 \mu \mathrm{M}$ to $100 \mu \mathrm{M}$ increased HUVEC tube formation. Oxycodone at the same concentrations significantly increased HUVEC tube formation. Fentanyl at $0.1 \mu \mathrm{M}$, $1 \mu \mathrm{M}$ and $10 \mu \mathrm{M}$ increased HUVEC tube formation. Morphine, fentanyl and oxycodone at $10 \mu \mathrm{M}$ stimulates tube formation by $\sim 2.3, \sim 2.3$ and $\sim 1.6$ fold, respectively, suggesting that morphine and fentanyl are more potent than oxycodone. Interestingly, morphine and oxycodone at $1000 \mu \mathrm{M}$ sharply decreased tube formation. There was a gradual loss of stimulation of tube formation by fentanyl at $100 \mu \mathrm{M}$ and $1000 \mu \mathrm{M}$. In contrast, codeine at all tested concentrations did not affect tube
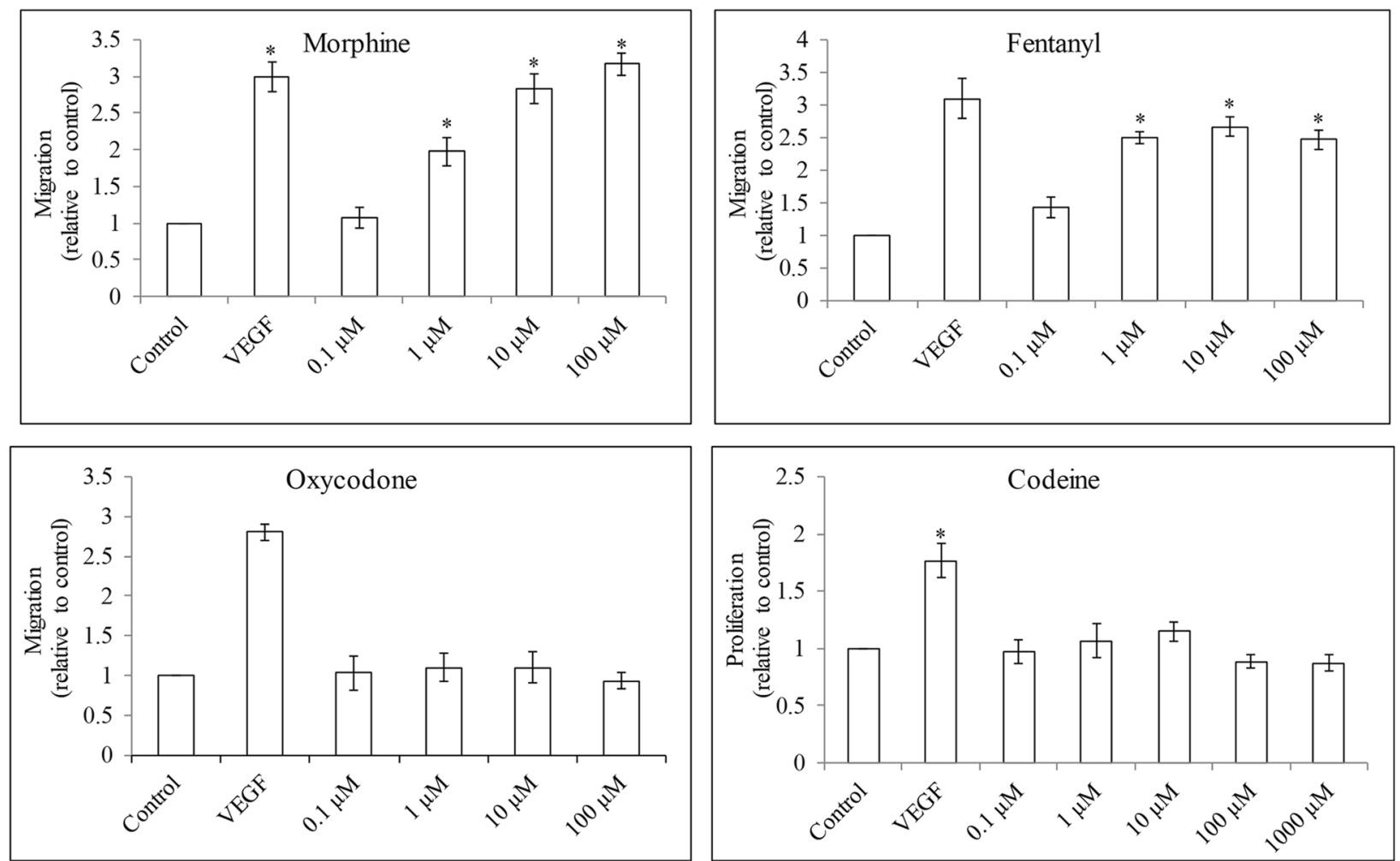

Fig. 3 The effects of opioids in HUVEC migration. Morphine, fentanyl and oxycodone at $0.1 \mu \mathrm{M}$ to $100 \mu \mathrm{M}$ increased migration in HUVECs. Codeine at $0.1 \mu \mathrm{M}$ to $100 \mu \mathrm{M}$ did not affect HUVEC migration. VEGF at $15 \mathrm{ng} / \mathrm{ml}$ was used. Results shown are relative to control. Each experiment was repeated three times in triplicate, and each value indicates mean $\pm S D .{ }^{*} p<0.05$, compared to control 
formation at all. Our results demonstrate that three out of four tested opioids display pro-angiogenic activities.

\section{Four opioids display differential effects on HUVEC growth, migration and survival}

To evaluate if opioids stimulate HUVEC proliferation, we assessed BrdU level after $24 \mathrm{~h}$ opioid treatment under serum-reduced culture condition. Consistent with the stimulated angiogenesis, VEGF increased HUVEC proliferation by 2 -fold compared with control (Fig. 2). We observed that morphine and oxycodone at $0.1 \mu \mathrm{M}$ to $100 \mu \mathrm{M}$ increased cell proliferation by 1.6 - and 1.4-fold, respectively. Fentanyl at $0.1 \mu \mathrm{M}$ to $10 \mu \mathrm{M}$ increased proliferation by 1.8 -fold but at $100 \mu \mathrm{M}$ and $1000 \mu \mathrm{M}$ demonstrated gradual loss of proliferation stimulation. Morphine, fentanyl and oxycodone at $1000 \mu \mathrm{M}$ decreased cell proliferation. Codeine at all tested concentrations did not affect HUVEC proliferation.

To evaluate the effect of opioids on HUVEC migration, we performed three-dimensional Boyden chamber migration assay which is informative and similar to an in-vivo migration context. We found that morphine and fentanyl but not oxycodone or codeine at $0.1 \mu \mathrm{M}$ to $100 \mu \mathrm{M}$ significantly increased HUVEC migration (Fig. 3 and Figure S5). We further evaluated if opioids can protect HUVEC from apoptosis induced by growth factor reduction, we assessed oligonucleosomal DNA fragments after $24 \mathrm{~h}$ opioid treatment under growth factor-reduced culture condition. As a positive control, VEGF decreased HUVEC apoptosis compared with control (Fig. 4). Morphine and fentanyl but not oxycodone at $0.1 \mu \mathrm{M}$ to $100 \mu \mathrm{M}$ decreased apoptosis. In contrast, morphine, fentanyl and oxycodone at $1000 \mu \mathrm{M}$ increased HUVEC apoptosis. Codeine at all tested concentrations did not affect HUVEC apoptosis. Morphine and fentanyl at 1, 10 and $100 \mu \mathrm{M}$ significantly decreased pro-apoptotic protein Bax without affecting Bcl-2 level (Fig. 5A and B). Consistently, Annexin V staining was significantly decreased in cells exposed to morphine and fentanyl (Fig. 5C and D and Figure S7). These clearly indicate the anti-apoptotic effect of morphine and fentanyl. Taken together, our results demonstrate the differential effects of four opioids on HUVEC growth, migration and survival.

\section{Opioids act on HUVEC in a $\mu$-opioid receptor-independent manner}

Morphine, fentanyl and oxycodone are known $\mu$-opioid receptor agonists. To investigate whether $\mu$-opioid
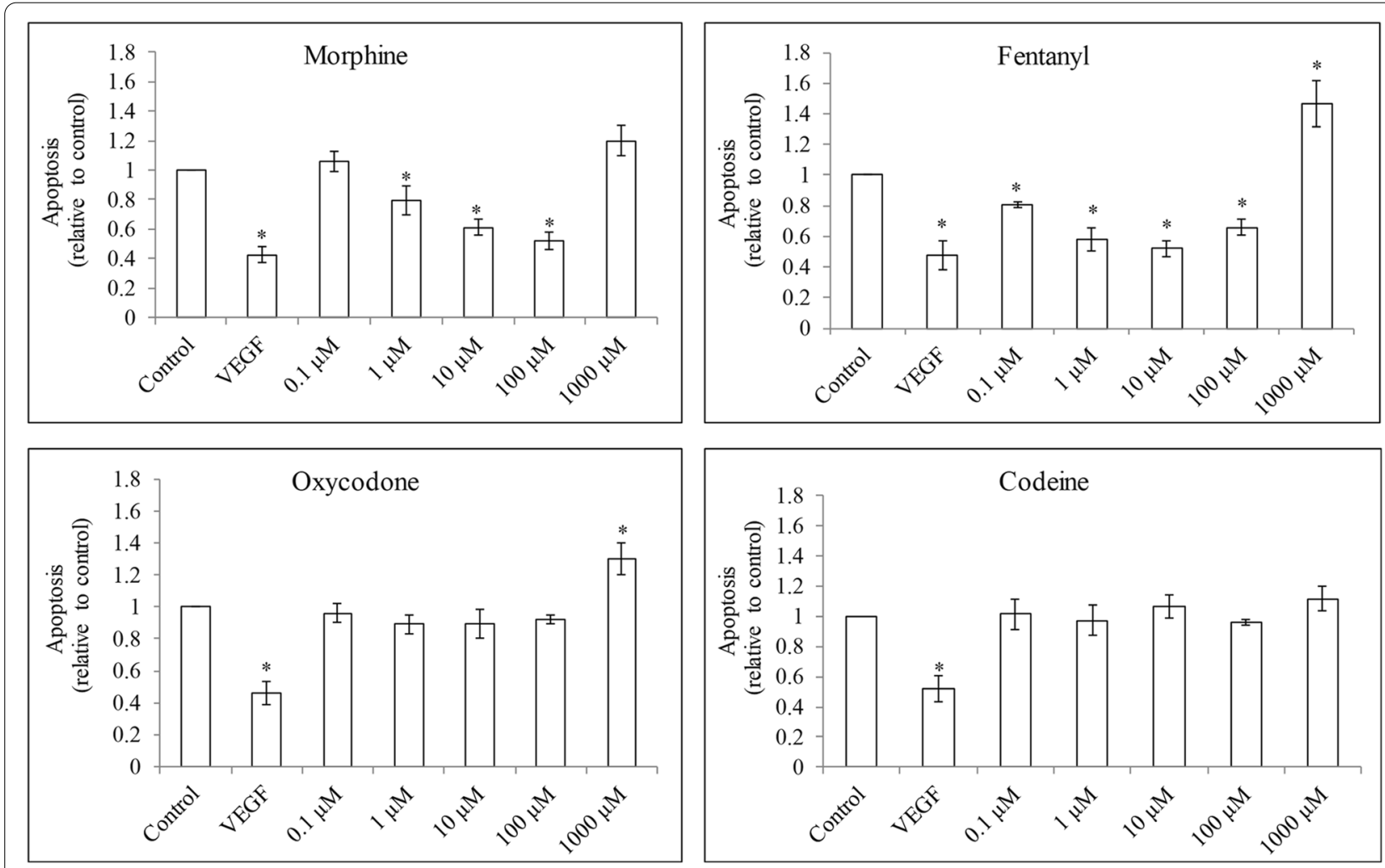

Fig. 4 The effects of opioids in HUVEC apoptosis. Morphine, fentanyl and oxycodone but not codeine at $0.1 \mu \mathrm{M}$ to $1000 \mu \mathrm{M}$ decreased apoptosis. VEGF at $15 \mathrm{ng} / \mathrm{ml}$ was used. Results shown are relative to control. Each experiment was repeated three times in triplicate, and each value indicates mean \pm SD. ${ }^{*} p<0.05$, compared to control 


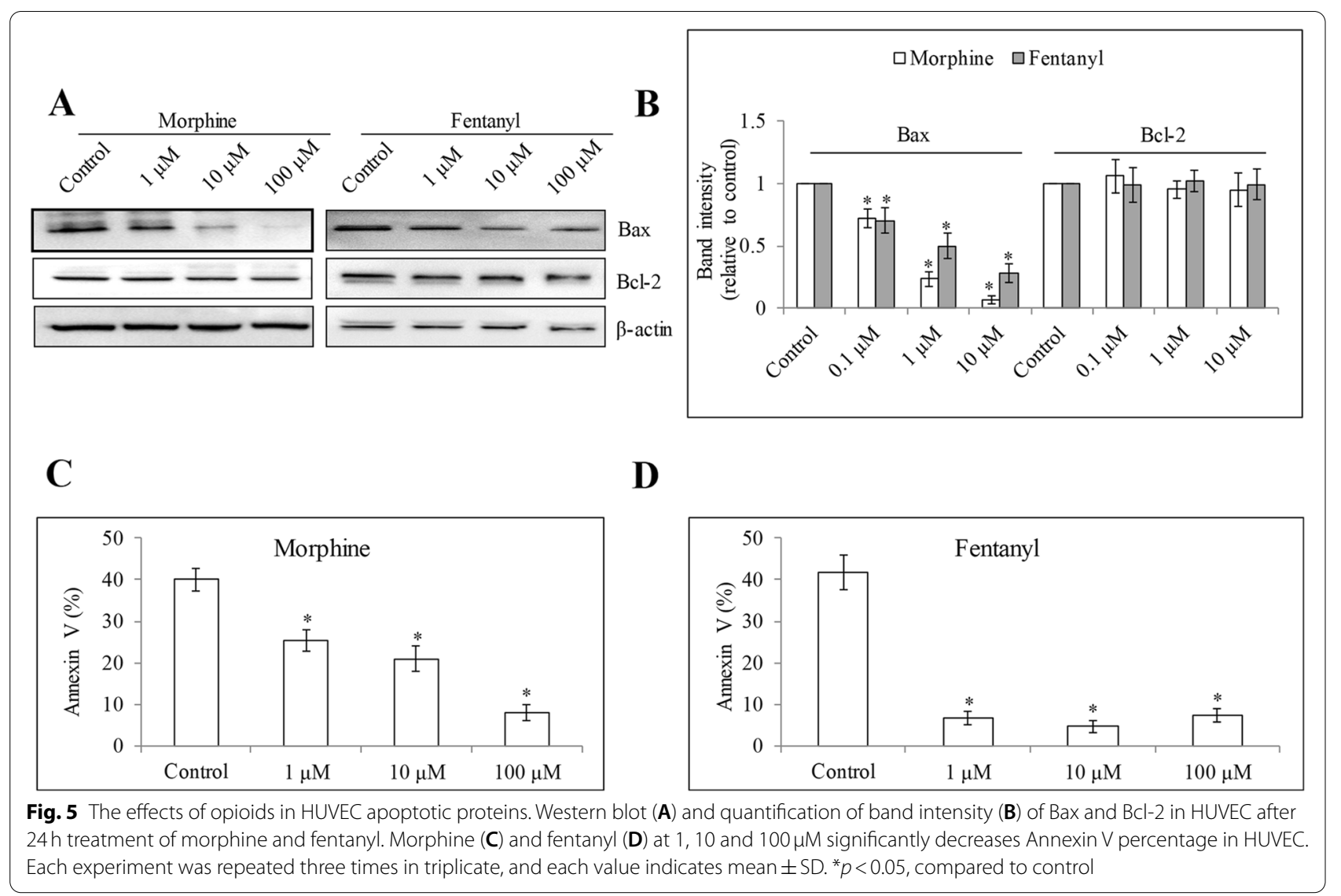

receptor is involved in these opioids' action in endothelial cells, we treated HUVEC with opioids in the absence or presence of naloxone which is a a $\mu$-opioid receptor antagonist) [24] and examined cell tube formation, proliferation and apoptosis. The concentration of naloxone used in our work is referred from the established reported literatures $[25,26]$. We found that naloxone did not antagonize morphine, fentanyl or oxycodone-induced capillary network formation (Fig. 6A) or endothelial cell growth (Fig. 6B). Naloxone did not antagonize morphine and fentanyl's anti-apoptosis effects in HUVEC (Fig. 6C). These demonstrate that opioids act on endothelial cells in a $\mu$-opioid receptor-independent manner. This is also consistent with our observation that naloxone alone did not affect endothelial cell tube formation, growth or survival (Fig. 4).

\section{Morphine but not fentanyl or oxycodone stimulates angiogenesis via MAPK activation}

Morphine and opioid receptor agonists have been shown to induce MAPK activation in endothelial cells to promote proliferation [27, 28]. Given our findings above, we performed western blot analysis of phosphor- and total p44/42 MAPK in HUVEC exposed to opioids. We found that morphine, fentanyl and oxycodone at $0.1 \mu \mathrm{M}, 1 \mu \mathrm{M}$ and $10 \mu \mathrm{M}$ increased p-p44/42 MAPK without affecting level of total MAPK (Fig. 7A, B and Figure S8). Codeine did not affect phosphor- nor total p44/42 MAPK (Fig. 7A, $\mathrm{B}$ and Figure S8). We performed rescue experiments using specific MAPK inhibitor PD98059 at concentration that has been shown to effectively block MARK signaling [28]. We found that PD98059 blocked morphine-induced endothelial cell tube formation, growth and survival (Fig. $7 \mathrm{C}$ to E). Interestingly, PD98059 did not rescue the pro-angiogenic, pro-proliferative and anti-apoptotic effects of fentanyl and oxycodone on endothelial cells (Fig. 7C to E). These results demonstrate that morphine but not fentanyl or oxycodone acts on endothelial cells via MAPK activation. We also performed immunoblotting analysis of angiogenic markers (eg, CD31, E-selection) and growth factor FGF in endothelial cells after opioids treatment. We found that all tested opioids did not affect CD31, E-selection and FGF levels in HUVEC (Figure S9 and S10). 


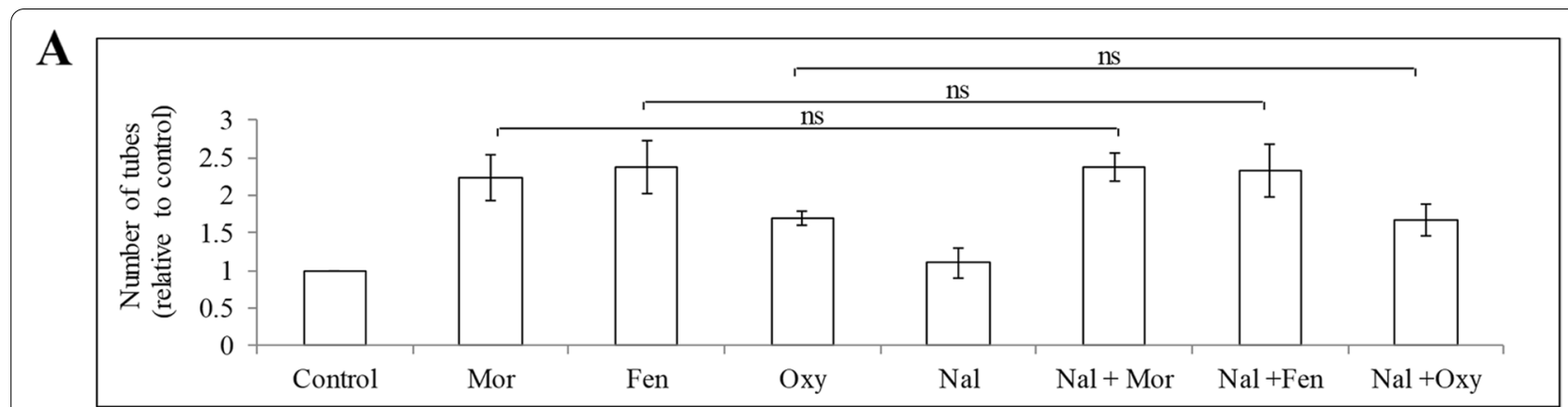

B

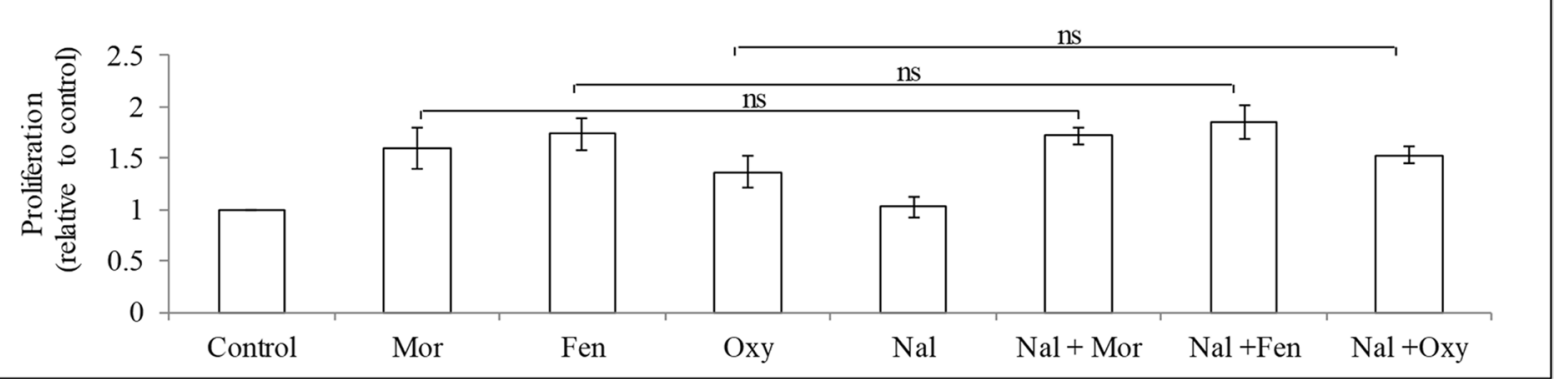

C

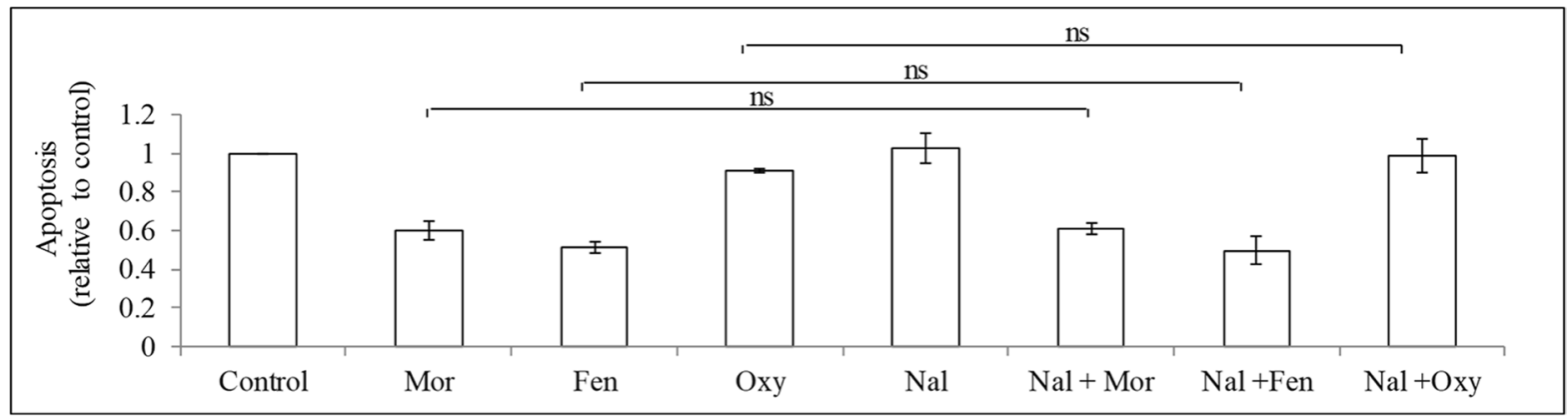

Fig. 6 The effects of opioids in HUVEC are opioid receptor-independent. Naloxone did not affect the effects of morphine, fentanyl and oxycodone in HUVEC capillary network formation (A), proliferation (B) and apoptosis (C). Naloxone at $10 \mu \mathrm{M}$ was used. Mor, morphine; Fen, fentanyl; Oxy, oxycodone; Nal, naloxone. Results shown are relative to control. Each experiment was repeated three times in triplicate, and each value indicates mean $\pm S D$

\section{Discussion}

Although substantial evidence have highlighted that perioperative anesthetic management of cancer patients could potentially affect longer-term recurrence and metastases [29], this requires confirmation in prospective, randomized clinical trials which will take many years to obtain data. Most studies have been conducting preclinical research using cell culture and animal models to investigate the direct role of anesthetic agents on cancer. In line with these efforts, we previously reported that sevoflurane, a volatile anesthetic agent, displays anti-cancer activities in cervical cancer [19]. Opioids are most commonly used medication for perioperative pain as well as cancer pain in cancer patients [30]. As cancer progression is largely dependent on angiogenesis, it is important to understand the influence of opioids on angiogenesis in order to guide the proper clinical use of opioids in cancer patients, particularly given that conclusions on the effects of opioids are contradictory. In this work, we show that three out of four opioids have stimulatory effects on angiogenesis, and furthermore that opioids stimulate angiogenesis via different mechanisms.

We firstly demonstrated that morphine at $0.1 \mu \mathrm{M}$ to $100 \mu \mathrm{M}$ stimulated endothelial cell tube formation, proliferation and survival under growth factor-reduced condition. Among the published research studies regarding the effects of morphine on neovascularization, stimulatory effect was observed in one half $[11,31]$ and inhibitory effect was observed in another half $[13,32]$. The reason behind this discrepancy is unclear, but it may be a result of differences in model systems, endothelial type, 


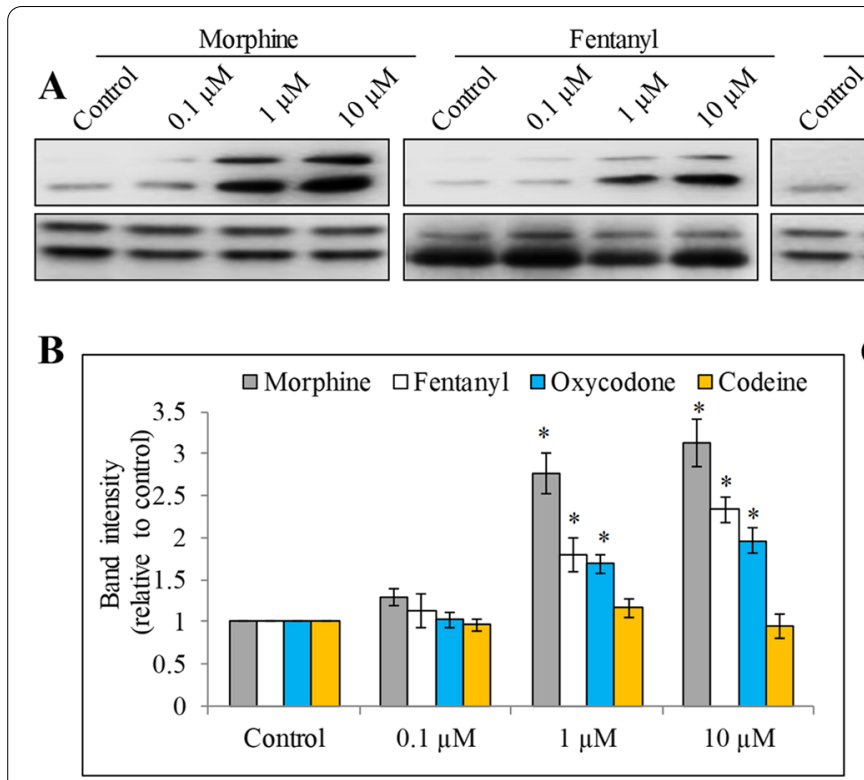

D
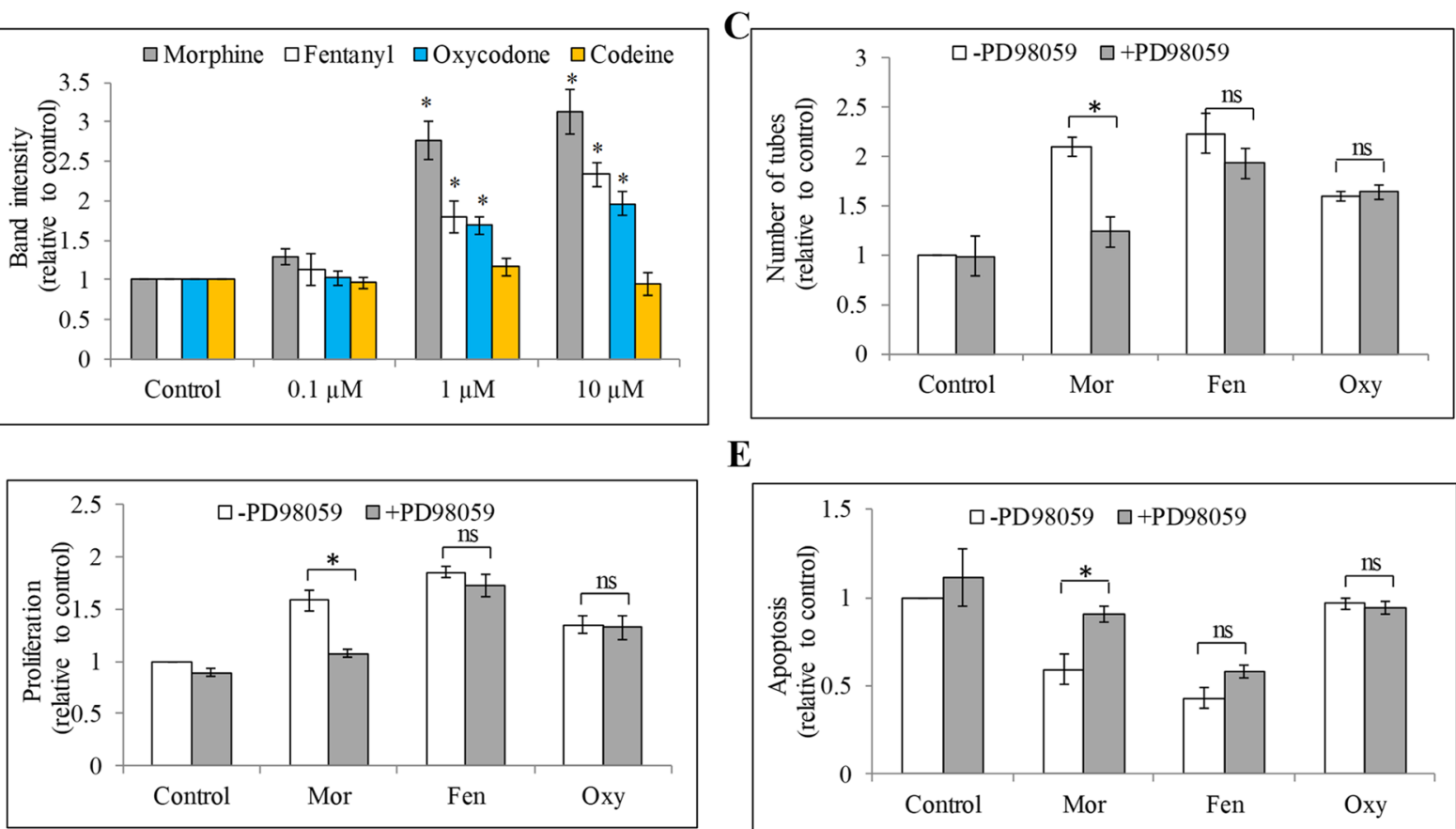

$\mathbf{E}$

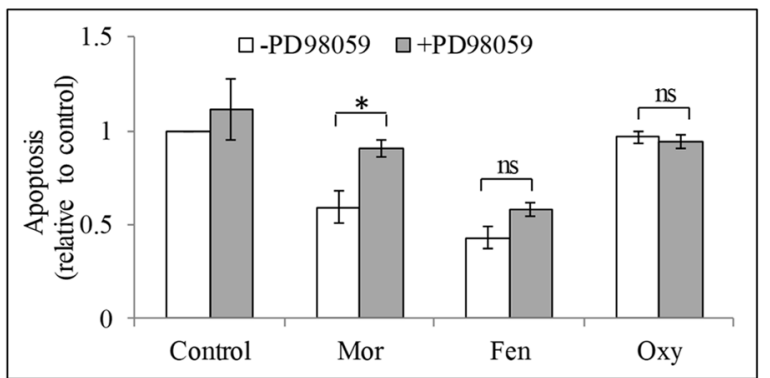

Fig. 7 Morphine but not fentanyl or oxycodone acts on HUVEC via MAPK activation. Western blots (A) and quantification of band intensity (B) of HUVEC exposed to morphine, fentanyl, oxycodone or codeine for $6 \mathrm{~h}$. MAPK inhibitor PD98059 (1 $\mu \mathrm{M})$ significantly reversed the effects of morphine but not fentanyl or oxycodone in stimulating capillary network formation (B), increasing proliferation (C) and decreasing apoptosis (D) in HUVEC. Results shown are relative to control. Each experiment was repeated three times in triplicate, and each value indicates mean \pm SD. ${ }^{*} p<0.05$, compared to -PD98059. ns, not significant. Relevant blot images were cropped to improve clarity

drug concentrations and experimental conditions. In support of this possibility, our finding is consistent with the recent study by Zhang et al. that morphine stimulates angiogenesis after serum deprivation [9] because our experimental settings are similar to Zhang et al's work. We next showed that oxycodone at the same concentration range also displayed pro-angiogenic activity, but was less potent than morphine. Fentanyl at $0.1 \mu \mathrm{M}$ to $10 \mu \mathrm{M}$ stimulates angiogenesis, which is supported by the recent study [15]. In addition, our findings further extend the previous study that fentanyl at higher concentrations (eg, $100 \mu \mathrm{M}$ and $1000 \mu \mathrm{M}$ ) gradually lost its stimulatory activity. The sharply reduced angiogenesis was observed in morphine, fentanyl and oxycodone at $1000 \mu \mathrm{M}$, suggesting that opioids at this concentration is likely toxic to endothelial cells. Codeine behaves differently on endothelial cells. We show that codeine up to $1000 \mu \mathrm{M}$ does not affect endothelial cell biology activities at all. In contrast, morphine and fentanyl demonstrate potent pro-angiogenic activities, and oxycodone demonstrates moderate pro-angiogenic activities. Using in vitro angiogenesis models, we and others consistently demonstrate the pro-angiogenetic effects of morphine and fentanyl $[15,28]$. It is worthy of confirming the effects of opioids on angiogenesis in vivo.

Although published studies have shown that the pro-angiogenic and anti-angiogenic activities of opioids were opioid-receptor based [7], our finding demonstrates that morphine acts on endothelial cells via $\mu$-opioid receptor-independent MAPK activation which is consistent with the previous report [28]. In contrast, fentanyl and oxycodone act on endothelial cells via other $\mu$-opioid receptor-independent mechanisms. Our findings that naloxone neither antagonizes opioids-induced 
angiogenesis nor induces angiogenesis by itself are also observed in human microvascular endothelial cells exposed to morphine and naloxone [28]. We further demonstrate that morphine, fentanyl and oxycodone but not codeine increase phosphorylation of $\mathrm{p} 44 / 42$ MAPK. A specific MAPK inhibitor reverses the effects of morphine but not fentanyl or oxycodone, indicating that only morphine acts on endothelial cells via MAPK activation and furthermore that fentanyl and oxycodone are via other mechanisms. Studies suggest that MAPK pathway is one of the downstream events of opioid receptor activation in endothelial cells [7]. Our work demonstrates that morphine activates MAPK in an opioid receptor-independent manner. MAPK is activated by receptor tyrosine kinases, $\mathrm{G}$ protein-coupled receptors and ion channels [33], which might be the upstream target of morphine. A recent work reveals that fentanyl simulates angiogenesis via promoting VEGFR2/FAK/ PI3K/Akt pathway and increasing activities of small GTPases [15]. We speculate that VEGFR2-mediated signaling might be involved in fentanyl's action. Oxycodone has been shown to stimulate cancer cell biological activities via regulating EGFR pathway [34]. Given the importance of EGFR in endothelial cells, we speculate that oxycodone might increase angiogenesis via promoting EGFR-mediated signaling.

We note that although morphine, fentanyl and oxycodone stimulate angiogenesis, the mechanisms of their action are different: morphine acts on endothelial cells via $\mu$-opioid receptor-independent MAPK activation whereas fentanyl and oxycodone act on endothelial cells via other $\mu$-opioid receptor-independent mechanisms. Although morphine, fentanyl, oxycodone and codeine belong to opioid family, they are independent drugs in aspects of their effects and underlying mechanisms on angiogenesis. The reasons on why codeine does not affect endothelial cell biology whereas the rest of the other three do are not clear. We speculate that the difference is less likely due to their activity on opioid receptor and is more likely due to their unrecognized pleiotropic effects.

In conclusion, our work on the comparative analysis of four opioids in endothelial cells demonstrates that opioids have differential effects on angiogenesis and there is no common mechanism for their action. Our work is the first to reveal the stimulatory effect of oxycodone on angiogenesis. The elaboration of mechanism action of each opioid in angiogenesis is worthy of further investigation.

\section{Abbreviations}

HUVEC: Human umbilical vein endothelial cell; VEGF: Vascular endothelial growth factor; EGFR: Epithelial growth factor receptor; VEGFR: Vascular endothelial growth factor receptor; MAPK: Mitogen-activated protein kinase; BrdU: Bromodeoxyuridine.

\section{Supplementary Information}

The online version contains supplementary material available at https://doi. org/10.1186/s12871-021-01475-7.

Additional file 1.

Acknowledgements

Not applicable.

Authors' contributions

TF and SZ designed the work. TF, JD, GC, BW, DGW, XL and KFW performed the experiments and analyzed the results. TF and SZ prepared the manuscript. The author(s) read and approved the final manuscript.

\section{Funding}

This work was supported by the following grants: Science Funds for Health and Family Planning Commission of Sichuan Province (18PJ157) and Chengdu Science and Technology (2018-YF05-00332-SN).

\section{Availability of data and materials}

The datasets used and/or analysed during the current study available from the corresponding author on reasonable request.

\section{Declarations}

Ethics approval and consent to participate

This study was conducted in accordance with the Declaration of Helsinki. All methods were carried out in accordance with relevant guidelines and regulations. All experimental protocols were approved by the institutional review board of Baoan Central Hospital of Shenzhen. Informed consent was obtained from all subjects.

Consent for publication

All authors reviewed and consented to the publication of the manuscript.

\section{Competing interests}

All authors declare no conflict of interest.

Received: 21 November 2020 Accepted: 7 October 2021

Published online: 26 October 2021

\section{References}

1. Zhang W, Liu JN, Tan XY. Vaccination with xenogeneic tumor endothelial proteins isolated in situ inhibits tumor angiogenesis and spontaneous metastasis. Int J Cancer. 2009;125(1):124-32.

2. Finn RS, Zhu AX. Targeting angiogenesis in hepatocellular carcinoma: focus on VEGF and bevacizumab. Expert Rev Anticancer Ther. 2009;9(4):503-9.

3. Pasternak GW. Opioids and their receptors: are we there yet? Neuropharmacology. 2014;76(Pt B):198-203.

4. Ondrovics M, Hoelbl-Kovacic A, Fux DA. Opioids: modulators of angiogenesis in wound healing and cancer. Oncotarget. 2017;8(15):25783-96

5. Eisenstein TK. The role of opioid receptors in immune system function. Front Immunol. 2019;10:2904.

6. Wigmore T, Farquhar-Smith P. Opioids and cancer: friend or foe? Curr Opin Support Palliat Care. 2016;10(2):109-18.

7. Mahbuba W, Lambert DG. Opioids and neovascularization; pro or anti? Br J Anaesth. 2015;115(6):821-4.

8. Stein C. Opioid Receptors. Annu Rev Med. 2016;67:433-51.

9. Zhang K, Huang W, Chen W, Zhou Q, Zhang Q, Wu X, et al. Morphine stimulates angiogenesis through Akt/mTOR/elF4E activation under 
serum deprivation or $\mathrm{H} 2 \mathrm{O} 2$-induced oxidative stress condition. Clin Exp Pharmacol Physiol. 2020;47(2):227-35.

10. Nishiwada T, Kawaraguchi Y, Uemura K, Kawaguchi M. Morphine inhibits cell viability and growth via suppression of vascular endothelial growth factor in human oral cancer HSC-3 cells. J Anesth. 2019.

11. Bimonte S, Barbieri A, Rea D, Palma G, Luciano A, Cuomo A, et al. Morphine promotes tumor angiogenesis and increases breast Cancer progression. Biomed Res Int. 2015;2015:161508.

12. Kim JY, Ahn HJ, Kim JK, Kim J, Lee SH, Chae HB. Morphine suppresses lung Cancer cell proliferation through the interaction with opioid growth factor receptor: an in vitro and human lung tissue study. Anesth Analg. 2016;123(6):1429-36.

13. Koodie L, Yuan H, Pumper JA, Yu H, Charboneau R, Ramkrishnan S, et al. Morphine inhibits migration of tumor-infiltrating leukocytes and suppresses angiogenesis associated with tumor growth in mice. Am J Pathol. 2014;184(4):1073-84.

14. Gupta M, Poonawala T, Farooqui M, Ericson ME, Gupta K. Topical fentanyl stimulates healing of ischemic wounds in diabetic rats. J Diabetes. 2015;7(4):573-83.

15. Liu W, Chen Y, Xu W, Wang W, Tang L, Xia R, et al. Fentanyl stimulates tumor angiogenesis via activating multiple pro-angiogenic signaling pathways. Biochem Biophys Res Commun. 2020;532(2):225-30

16. Crampton SP, Davis J, Hughes CC. Isolation of human umbilical vein endothelial cells (HUVEC). Journal of visualized experiments : JoVE. 2007;3:183.

17. Arnaoutova I, Kleinman HK. In vitro angiogenesis: endothelial cell tube formation on gelled basement membrane extract. Nat Protoc 2010;5(4):628-35.

18. Salic A, Mitchison TJ. A chemical method for fast and sensitive detection of DNA synthesis in vivo. Proc Natl Acad Sci U S A. 2008;105(7):2415-20.

19. Ding J, Zhang L, Zeng S, Feng T. Clinically relevant concentration of sevoflurane suppresses cervical cancer growth and migration through targeting multiple oncogenic pathways. Biochem Biophys Res Commun. 2019;514(4):1179-84.

20. Nagata S, Nagase H, Kawane K, Mukae N, Fukuyama H. Degradation of chromosomal DNA during apoptosis. Cell Death Differ. 2003;10(1):108-16.

21. Liu ZQ, Mahmood T, Yang PC. Western blot: technique, theory and trouble shooting. N Am J Med Sci. 2014;6(3):160.

22. Cao Y, Gong Y, Liu L, Zhou Y, Fang X, Zhang C, et al. The use of human umbilical vein endothelial cells (HUVECs) as an in vitro model to assess the toxicity of nanoparticles to endothelium: a review. J Appl Toxicol. 2017;37(12):1359-69.

23. Olsson AK, Dimberg A, Kreuger J, Claesson-Welsh L. VEGF receptor signalling - in control of vascular function. Nat Rev Mol Cell Biol. 2006;7(5):359-71.

24. Olianas MC, Concas D, Onali P. Agonist activity of naloxone benzoylhydrazone at recombinant and native opioid receptors. Br J Pharmacol. 2006;147(4):360-70.

25. Rozenfeld-Granot G, Toren A, Amariglio N, Nagler A, Rosenthal E, Biniaminov $\mathrm{M}$, et al. MAP kinase activation by mu opioid receptor in cord blood CD34(+)CD38(-) cells. Exp Hematol. 2002;30(5):473-80.

26. Dai S, Zhang X, Zhang P, Zheng X, Pang Q. Fentanyl inhibits acute myeloid leukemia differentiated cells and committed progenitors via opioid receptor-independent suppression of Ras and STAT5 pathways. Fundam Clin Pharmacol. 2021;35(1):174-83.

27. Leo S, Nuydens R, Meert TF. Opioid-induced proliferation of vascular endothelial cells. J Pain Res. 2009;2:59-66.

28. Gupta K, Kshirsagar S, Chang L, Schwartz R, Law PY, Yee D, et al. Morphine stimulates angiogenesis by activating proangiogenic and survivalpromoting signaling and promotes breast tumor growth. Cancer Res. 2002;62(15):4491-8

29. Mao L, Lin S, Lin J. The effects of anesthetics on tumor progression. Int J Physiol Pathophysiol Pharmacol. 2013;5(1):1-10.

30. Bugada D, Lorini LF, Fumagalli R, Allegri M. Genetics and opioids: towards more appropriate prescription in cancer pain. Cancers (Basel). 2020;12(7).

31. Gupta K, Chen C, Lutty GA, Hebbel RP. Morphine promotes neovascularizing retinopathy in sickle transgeneic mice. Blood Adv. 2019;3(7):1073-83.

32. Karaman H, Tufek A, Karaman E, Tokgoz O. Opioids Inhibit Angiogenesis in a Chorioallantoic Membrane Model. Pain Physician. 2017;20(2S):SE11-21.

33. Wortzel I, Seger R. The ERK Cascade: distinct functions within various subcellular organelles. Genes \& cancer. 2011:2(3):195-209.

34. Yu Y, Li D, Duan J, Xu H, Li L, Tan D, et al. The pro- and anti-cancer effects of oxycodone are associated with epithelial growth factor receptor level in cancer cells. Biosci Rep. 2020;40(2).

\section{Publisher's Note}

Springer Nature remains neutral with regard to jurisdictional claims in published maps and institutional affiliations.
Ready to submit your research? Choose BMC and benefit from:

- fast, convenient online submission

- thorough peer review by experienced researchers in your field

- rapid publication on acceptance

- support for research data, including large and complex data types

- gold Open Access which fosters wider collaboration and increased citations

- maximum visibility for your research: over $100 \mathrm{M}$ website views per year

At BMC, research is always in progress.

Learn more biomedcentral.com/submissions 